\title{
BACTERIOCIN PRODUCTION AND PROBIOTIC PROPERTIES OF ENTEROCOCCUS SPP. ISOLATED FROM RAW MILK
}

\author{
AHMED MOUSTAFA HAMMAD
}

Laboratory of Food Hygiene and Control, Faculty of Veterinary Medicine, University of Sadat City, Sadat City, Egypt.

\section{ABSTRACT}

Received at: $29 / 6 / 2015$

Accepted: 28/7/2015
Little is known about using Enterococcus strains as probiotics in the dairy industry in the Middle East. The aim of this study was to analyze the probiotic properties of Enterococcus spp. isolated from 75 raw milk samples. Overall, 65 milk samples $(86.66 \%, 65 / 75)$ analyzed were contaminated with enterococci. 70 presumptive enterococcal isolates were recovered, and 60 isolates were confirmed by PCR as Enterococcus spp. E. faecium and E. faecalis were detected in 28 (28/60) and 12 $(12 / 60)$ of isolates, respectively. Fifteen isolates showed negative results in safety relevant characteristics including antibiotic susceptibility and virulence gene profile. Seven strains showed antimicrobial activities towards Staphylococcus aureus and two strains showed antimicrobial activities against Listeria monocytogenes and 6 strains showed antimicrobial activities towards both pathogens. None of the isolates showed antimicrobial activities towards Gram negative bacteria tested in this study. Some strains showed survival in gastric juice after 2 hours and all isolates showed survival in different degree in bile after 24 hours. PCR analysis revealed that six strains carried both enterocins A and B. Neither enterocin L nor enterocin P genes were detected in isolated strains. In conclusion, the results obtained in this study showed that six E. faecium strains have great potential to be used as probiotic organisms in human food and/or animal feed.

Key words: Bacteriocin, Probiotic, Enterococcus spp., Raw milk

\section{INTRODUCTION}

The increasing number of foodborne illnesses caused by microbial contamination, and the increasing consumer conscience of the risks resulting from chemical preservatives made the discovery of natural inhibitory substances active against foodborne pathogens an important topic in the last few years. Enterococci mainly occur as non-starter lactic acid bacteria in different types of cheeses produced worldwide. Some strains have different applications in the dairy industry. As starters or adjunct cultures, these LAB play an important role in improving flavour and quality of different types of cheeses such as Cheddar, Feta, Mozzarella, and Hispanico (Malek et al., 2012). The species Enterococcus faecium, Enterococcus faecalis, and Enterococcus durans have been characterized in some of these studies (Moreno et al., 2006; Sarantinopoulos et al., 2001). For example, E. faecium K77D was approved by the British "Advisory Committee on Novel Foods and Processes" (ACNFP, 1996) as starter culture for manufacturing of fermented dairy products and E. faecium PR88 was used as a probiotic in Cheddar cheese (Giraffa, 2003).
Numerous strains of enterococci associated with food systems, mainly E. faecium and E. faecalis, are capable of producing a variety of bacteriocin called entericin with broad spectrum activity. Bacteriocins are defined as ribosomal antimicrobial peptides that are produced by some bacteria to inhibit the growth of similar, closely related or non-related bacteria. There are several approaches have been taken to categorize bacteriocins including producing strain, common resistance mechanisms, and mechanism of killing (Zouhir et al., 2010). One, which is used to classify the bacteriocins into 3 classes; Class I peptides, which undergo post-translational modification (lantibiotics). Class II peptides, which are heat-stable and largely unmodified and further sub-divided into 3 classes; namely, class IIa (Listeria active peptides), class IIb (2-peptide bacteriocins), and class IIc (cyclic peptides). Class III bacteriocins comprises high-molecular-weight and heat unstable bacteriocins (Yi et al., 2010). Bacteriocins become one of the weapons against bacteria due to the specific characteristics of large diversity of structure and function, natural resource, and being stable to heat (Goh and Philip, 2015). There have been numerous published reports on bacteriocin producing bacteria, primarily among strains of lactic acid 
bacteria (LAB) associated with food systems. Currently, the production of bacteriocin by enterococci is extensively studied due to their Generally Recognized As Safe (GRAS) status, since they prevent the growth of many food-borne pathogens and spoilage bacteria such as Staphylococcus aureus, Listeria monocytogenes, Escherichia coli, Pseudomonas spp., Bacillus spp. and Clostridium spp. (Aran et al., 2015). They can also be used in different food products in order to enhance their shelf life.

The World Health Organization (WHO) defines probiotics as, "Live microorganisms which, when administrated in adequate amounts, confer a health benefit on the host" (Dobson et al., 2012). The characteristics of probiotics should include: a group of strains beneficial to the host animal that can stably survive and have metabolic activity in the intestinal environment, and being non-pathogenic and nontoxic, remain stable and viable for long periods of storage and harsh conditions (Vandenplas et al., 2015). However, even though enterococci are now being used as probiotics but they are also among the most common nosocomial pathogens associated with many human infections. They are known to cause endocarditis, bacteremia, and urinary tract, central nervous system, intraabdominal, and pelvic infections, and can cause multiple antibiotic resistance (Fisher and Phillip, 2009). Most of the pathogenic strains are multi-antibiotic resistant and produce adhesins, invasins, pili, and hemolysin (Rehaiem et al., 2014). Therefore, the objective of this study was to characterize the properties of Enterococcus spp. isolated from raw milk, in order to determine their abilities to produce bacteriocins and theirprobiotic properties.

\section{MATERIALS and METHODS}

\section{Isolation and identification of Enterococcus spp.}

Samples $(n=75)$ of raw milk were collected from different supermarkets, retail and dairy shops in ElMenofia province, Egypt, over a period of 5 months (from December 2014 to April 2015). Samples were immediately placed on ice for transportation. In the laboratory, $25 \mathrm{ml}$ of raw milk was mixed with $225 \mathrm{ml}$ of buffered peptone water (BD Diagnostic Systems, Sparks, MD, USA) in sterile wide-mouth jars. The homogenate $(0.1 \mathrm{ml})$ was transferred to kanamycin aesculinazide (KAA) agar (Merck, Darmstadt, Germany). Following $24 \mathrm{~h}$ incubation at $35^{\circ} \mathrm{C}$, three morphologically different colonies from the KAA were inoculated onto Columbia sheep's blood agar (Merck) as described previously (Domig et al., 2003). Presumptive identification of enterococci was made based on colony morphology, catalase test, pyrrolidonyl arylamidase test (Oxoid, Basingstoke, England), and growth in brain-heart infusion broth with $6.5 \% \mathrm{NaCl}$.

\section{DNA extraction and species identification}

Total genomic DNA was prepared using a DNeasy Tissue kit (Qiagen,). The genus Enterococcus was confirmed using specific primers E1 and E2 as described by Deasy et al. (2000). Multiplex PCR was used to identify four common species: E. faecalis, E. faecium, E. casseliflavus, and E. gallinarum (Kariyama et al., 2000).

\section{Detection of safety-relevant characteristic Antibiotic susceptibility}

All isolates were characterized by antimicrobial susceptibility testing for 17 antibiotics by a disc diffusion method in accordance with the Clinical and Laboratory Standards Institute guidelines (Clinical and Laboratory Standards Institute, 2011). The 17 antibiotics tested comprised aminoglycosides (kanamycin [30 $\mu \mathrm{g}$ ], gentamicin [10 $\mu \mathrm{g}]$, and streptomycin $[10 \mu \mathrm{g}]$ ), cephalosporins (cefotaxime [30 $\mu \mathrm{g}]$ and cefoperazone [75 $\mu \mathrm{g}]$ ), a fluoroquinolone (ciprofloxacin [5 $\mu \mathrm{g}]$ ), glycopeptides (teicoplanin [30 $\mu \mathrm{g}]$ and vancomycin $[30 \mu \mathrm{g}])$, a lincosamide (clindamycin $[2 \mu \mathrm{g}]$ ), macrolides (azithromycin [15 $\mu \mathrm{g}$ ], clarithromycin [15 $\mu \mathrm{g}]$, and erythromycin [15 $\mu \mathrm{g}]$ ), penicillins (ampicillin $\quad\left[\begin{array}{ll}10 & \mu \mathrm{g}\end{array}\right]$, amoxicillin/clavulanic acid $\left[\begin{array}{llll}20 & \mu \mathrm{g} / 10 & \mu \mathrm{g}\end{array}\right]$, and oxacillin $\left.\left[\begin{array}{ll}1 & \mu \mathrm{g}\end{array}\right]\right)$, tetracycline $(30 \mu \mathrm{g})$, and chloramphenicol $(30 \mu \mathrm{g})$.

\section{Screening of E.faecalis and E. faecium for virulence genes}

All E.faecalis and E. faecium isolates were screened for five putative virulence determinants, including asal (aggregation substance), cylA (cytolysin), esp (Enterococcus surfaceprotein), gel E (gelatinase), and hyl (hyaluronidase), using multiplex PCR as described previously (Vankerckhoven et al., 2004).

\section{Gastric Juice and Bile Tolerance}

For tolerance to the gastric juice, $3 \mathrm{mg} / \mathrm{mL}$ pepsin was added into phosphate buffered saline adjusted to pH 2.5 (Lim and Im, 2009). To test bile tolerance, $0.3 \%$ bile salt was added to the MRS broth. Selected isolates were adjusted to OD $=0.4$ at $600 \mathrm{~nm}$ and $1 \%$ of each isolate was inoculated into the artificial gastric juice and bile solution. The inoculated solutions were incubated at $37^{\circ} \mathrm{C}$ and viable bacterial cells were counted at 0 and $2 \mathrm{~h}$ for the gastric juice tolerance and 0 and $24 \mathrm{~h}$ for the bile tolerance.

\section{Antibacterial spectrum}

An antibacterial spectrum was performed, by agar well diffusion assays as previously described by García-Cano et al. (2014). Fifteen milliliters of 1 $\mathrm{g} / 100 \mathrm{ml}$ (brain heart infusion) BHI agar were poured in petri dishes and let solidify then $10 \mathrm{ml}$ of agar $(0.8 \mathrm{~g} / 100 \mathrm{ml})$ containing $107 \mathrm{CFU} / \mathrm{ml}$ of tested bacteria were added. The microorganisms tested were obtained from our laboratory including: S. aureus SRM-47, Listeria monocytogenes LRM- 
15, Salmonella enterica typhimurium SSRM-45, E. coli ERM-18, and Aeromonas hydrophila ARM-95.

\section{PCR detection of enterocin genes}

PCR amplification of enterocin genes coding for enterocin A (entA), enterocin B (entB), enterocin $\mathrm{P}$ (entP), and enterocin L50 (ent L50 A and ent L5OB) were carried out as previously described (DuToit et al., 2000). PCR was performed on a DNA thermal cycler in a final volume of $50 \mathrm{ml}$ containing $1 \times \mathrm{PCR}$ buffer, $1.5 \mathrm{mM} \mathrm{MgCl} 2,200 \mathrm{mM}$ of each of the four dNTPs, $0.5 \mathrm{mM}$ of each primer and 1.25 units of Taq DNA polymerase. The PCR conditions were 35 cycles of denaturation at $95{ }^{\circ} \mathrm{C}$ for $5 \mathrm{~min}$, annealing at different annealing temperatures, and $72{ }^{\circ} \mathrm{C}$ for 30 s. The PCR products were resolved by electrophoresis in $1.5 \%$ agarose gels.

\section{RESULTS}

\section{Characteristics of isolated strains}

Overall, 65 milk samples $(86.66 \%, 65 / 75)$ analyzed were contaminated with enterococci. The current study recovered 70 presumptive enterococcal isolates, and 60 isolates were confirmed by PCR as Enterococcus spp. E. faecium and E. faecalis were detected in 28 (28/60) and 12 (12/60) of isolates, respectively.
Forty five isolates showed resistance to one or more antibiotic tested and some carried virulence genes. Twenty five isolates showed negative results in safety relevant characteristics including antibiotic susceptibility and virulence gene profile. These isolates were further analyzed.

\section{Antibacterial spectrum}

As shown in Table 1, seven strains showed antibacterial activities towards S.aureus and two strains showed antibacterial activities against L.monocytogenes and 6 strains showed antibacterial activities towards both pathogens. None of the isolates showed antimicrobial activities towards Gram negative bacteria.

\section{Incidence of enterocin genes}

As shown in Fig. 1 and 2, both enterocins A and B genes were detected in sixstrains (ERM-5, ERM-9, ERM-10, ERM-12, ERM-22, and ERM-30). Neither enterocin $\mathrm{L}$ nor enterocin $\mathrm{P}$ genes were detected in isolated strains.

\section{Gastric juice and bile tolerance}

As shown in Table2, six strains (ERM-5, ERM-9, ERM-10, ERM-12, ERM-22, and ERM-30) showed survival in large number in gastric juice after 2 hours and all isolates survived in bile with different degrees after 24 hours.

\section{Safety evaluation}

Table 1: Antibacterial activity of Enterococcus spp. against indicator strains.

\begin{tabular}{|c|c|c|c|c|c|}
\hline \multirow[t]{2}{*}{ Strains } & \multicolumn{4}{|c|}{ Indicator strains } & \multirow[b]{2}{*}{$\begin{array}{l}\text { A. hydrophila } \\
\text { ARM-95 }\end{array}$} \\
\hline & $\begin{array}{l}\text { L. monocytogenes } \\
\text { LRM-15 }\end{array}$ & $\begin{array}{l}\text { S. aureus } \\
\text { SRM-47 }\end{array}$ & $\begin{array}{c}\text { Salmonella typhimurium } \\
\text { SSRM-45 }\end{array}$ & $\begin{array}{c}\text { E. coli O157 ERM- } \\
18\end{array}$ & \\
\hline ERM-3 & + & - & - & - & - \\
\hline ERM-5 & + & + & - & - & - \\
\hline ERM-6 & + & - & - & - & - \\
\hline ERM-9 & + & + & - & - & - \\
\hline ERM-10 & + & + & - & - & - \\
\hline ERM-12 & + & + & - & - & - \\
\hline ERM-17 & + & - & - & - & - \\
\hline ERM-21 & + & - & - & - & - \\
\hline ERM-22 & + & + & - & - & - \\
\hline ERM-25 & + & - & - & - & - \\
\hline ERM-26 & - & + & - & - & - \\
\hline ERM-28 & + & - & - & - & - \\
\hline ERM-30 & + & + & - & - & - \\
\hline ERM-31 & - & + & - & - & - \\
\hline ERM-32 & + & - & - & - & - \\
\hline
\end{tabular}


Assiut Vet. Med. J. Vol. 61 No. 146 July 2015

Table 2: Tolerance of selected Enterococcus strains to artificial gastric juice at 0 and $2 \mathrm{~h}$.

\begin{tabular}{|c|c|c|c|}
\hline \multirow[t]{2}{*}{ Strains } & \multirow[t]{2}{*}{ Species } & \multicolumn{2}{|c|}{ Tolerance to gastric juice $(\log \mathrm{cfu} / \mathrm{mL})$} \\
\hline & & Initial population ( 0 h) & After 2 h \\
\hline ERM-3 & E. faecalis & $6.63 \pm 0.06$ & $3.77 \pm 0.1$ \\
\hline ERM-5 & E. faecium & $6.88 \pm 0.19$ & $6.58 \pm 0.18$ \\
\hline ERM-6 & E. faecalis & $6.49 \pm 0.09$ & - \\
\hline ERM-9 & E. faecium & $6.68 \pm 0.25$ & $6.88 \pm 0.75$ \\
\hline ERM-10 & E. faecium & $6.63 \pm 0.06$ & $6.83 \pm 0.76$ \\
\hline ERM-12 & E. faecium & $6.51 \pm 0.00$ & $6.91 \pm 0.08$ \\
\hline ERM-17 & Enterococcus spp. & $6.68 \pm 0.31$ & $1.77 \pm 0.1$ \\
\hline ERM-21 & E. faecium & $6.69 \pm 0.03$ & - \\
\hline ERM-22 & E. faecium & $6.63 \pm 0.06$ & $6.63 \pm 0.25$ \\
\hline ERM-25 & E. faecalis & $6.88 \pm 0.19$ & $2.59 \pm 0.05$ \\
\hline ERM-26 & Enterococcus spp. & $6.49 \pm 0.09$ & - \\
\hline ERM-28 & E. faecalis & $6.93 \pm 0.06$ & $2.59 \pm 0.05$ \\
\hline ERM-30 & E. faecium & $6.73 \pm 0.08$ & $6.69 \pm 0.03$ \\
\hline ERM-31 & Enterococcus spp. & $6.28 \pm 0.11$ & $5.69 \pm 0.34$ \\
\hline ERM-32 & Enterococcus spp. & $6.59 \pm 0.08$ & $3.45 \pm 0.21$ \\
\hline
\end{tabular}

Values are means \pm standard deviation.-, none detected.

$$
\begin{array}{llllllllllllllll}
M & 3 & 5 & 6 & 9 & 10 & 12 & 17 & 21 & 22 & 25 & 26 & 28 & 30 & 31 & 32
\end{array}
$$

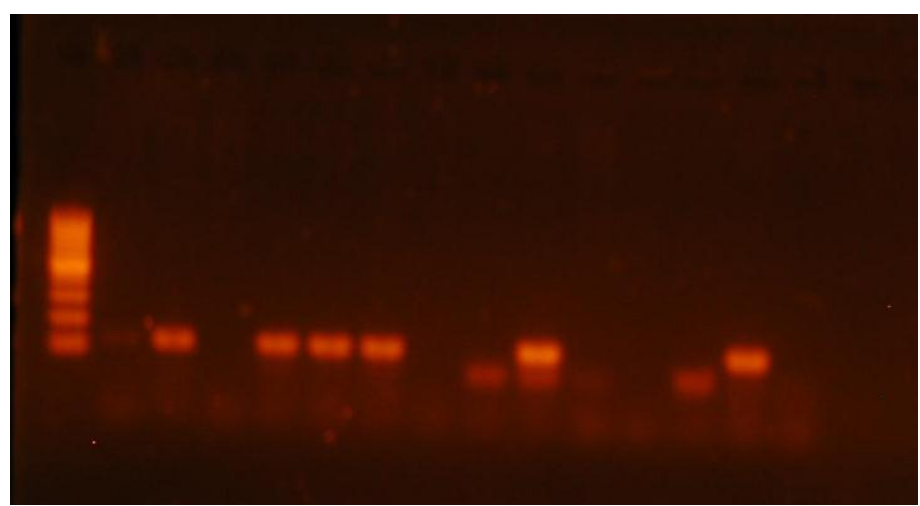

Fig. 1: Enterocin A gene screening. Electrophoresis analysis using 1.5\% agarose of PCR products.

M: 100 bp ladder EnterocinA gene: 126 bp

Positive strains: 5, 9, 10, 12, 22, 30

Negative strains: $3,6,17,21,25,26,28,31,32$

$\begin{array}{llllllllllllllll}M & 3 & 5 & 6 & 9 & 10 & 12 & 17 & 21 & 22 & 25 & 26 & 28 & 30 & 31 & 32\end{array}$

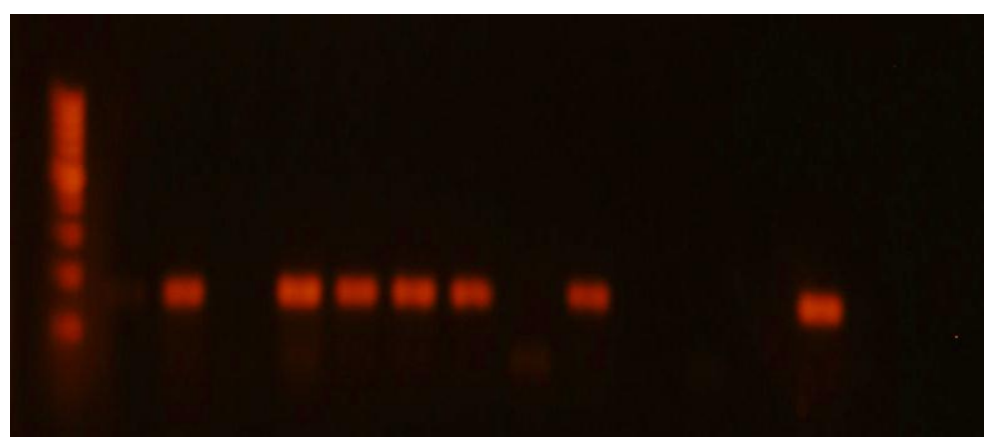

Fig. 2: Enterocin B gene screening. Electrophoresis analysis using 1.5\% agarose of PCR products.

M: 100 bp ladder Enterocin B gene: $162 \mathrm{bp}$

Positive strains: $5,9,10,12,17,22,30$

Negative strains: 3, 6, 21, 25, 26, 28, 31, 32 


\section{DISCUSSION}

The risks resulting from chemical preservatives used to control foodborne pathogens has led to continued drive to find novel bacteriocins that can control food pathogens more effectively. Food strains of enterococci were found to harbour antibiotic resistance and virulence genes normally located in conjugative plasmids, increasing the risk of genetic transfer (Eaton and Gasson, 2001). The presence and expression of virulence determinants and antibiotic resistance in enterococci isolates raises concerns on their applications in foods. Therefore, the potential pathogenicity and antibiotic resistance of bacteriocin producers was evaluated in this study by investigating the presence of virulence factors and antibiotic resistance patterns. Remarkably, 25 Enterococcus spp. tested negative for all the virulence genes assayed and showed susceptibility to all tested antibiotics. These results confirm the safety of using these strains for manufacture of fermented dairy products.

The antibacterial activity of Enterococcus spp against food borne pathogens included Gram positive and negative bacteria. It has also been reported that bacteriocin-producing strains of $E$. faecium is of great potential in dairy technology (Banwo et al., 2013). In this study, 15 strains have antibacterial activities. The strain's spectrum of antimicrobial activity includes Gram-positive bacteria, L. monocytogenes and S.aureus. Notably, $L$. monocytogenes is a widely distributed food borne pathogen with characteristics such as growth temperatures from 1 to $45^{\circ} \mathrm{C}$, high tolerance to salt and low $\mathrm{pH}$, which make it difficult to control in food. Additionally, S. aureus, is among the most common foodborne pathogens worldwide. However, little is known about the antimicrobial effect of Enterococcus spp. on these pathogens. In the present study, six strains showed antimicrobial activities against both pathogens (Table 1) indicating their significance potential for biocontrol of both pathogens in dairy products.

The purified DNA of isolated strains was subjected to PCR amplification to determine the existence of structural genes encoding the described enterocins (entA, entB, entP, entL50A/entL50B), all known to be readily spread among enterococci (Du Toit et al., 2000). The PCR results (Fig. 1 and 2) indicated that enterocins $\mathrm{A}$ and $\mathrm{B}$ are highly prevalent in the isolated strains. According to the classification scheme of Franz et al. (2007), enterocins A is grouped in the class IIa bacteriocins (pediocin-like bacteriocins), which have a very effective antilisterial activity, and enterocin B is grouped in the class II.3 bacteriocins. Casaus et al. (1997) reported that enterocin B exhibited synergistic activity with enterocin A. Fortunately, six strains isolated in this study carried both enterocins A and B genes (ERM5, ERM-9, ERM-10, ERM-12, ERM-22, ERM-30). Interestingly, production of multiple bacteriocins is not unusual and seems to be a common feature of enterococci. It has been reported that many enterococci produce multiple bacteriocins, such as $E$. faecium WHE81 E. faecium KV-B5, E. faecium NKR-5-3A, E. faecium DAC2 and E. faecium JCM 5804T. According to several studies, the multiple enterocins-producing isolates are likely more efficient and might show a broader range of inhibition in preventing the growth of undesirable bacteria than a simple bacteriocin producer (Ishibashi et al., 2012). According to Sanchez et al. (2007), the coproduction of enterocin A and enterocin $\mathrm{P}$ by E. faecium DAC2 produces a higher antagonistic activity than those of the controls $E$. faecium $\mathrm{P} 13$ (producer of enterocin $\mathrm{P}$ ) and $E$. faecium T136 (producer of enterocin A). In this study, the co-production and variability of enterocin genes in enterococcal strains detected in our study is probably facilitated by the horizontal gene transfer among enterococcal strains and by the well-known ability of enterococci to incorporate DNA material. The acquisition of multiple bacteriocins by $E$. faecium may not only be useful to antagonize various microbial pathogenic and spoilage bacteria, but also to confer a selective advantage and enhance intra specific competition of the strain against other competitors for the microbiological niches (Rehaiem et al., 2014). Moreover, in populations where the dominant bacteriocinogenic strain produces multiple bacteriocins, the development of resistant bacteria could be slowed down in comparison with the populations in which the dominant producer synthesizes a single bacteriocin (Tessema et al., 2009). Of note, the isolated strains carried both enterocins A and B showed antimicrobial effect against both $S$. aureus and L. monocytogenes (Table 1).

When selecting a probiotic strain a number of aspects should be considered and the theoretical basis for selection should involve functional as well as desirable technological properties (FAO/WHO, 2002). Examples of desirable characteristics for a probiotic strain include the ability to survive and retain viability at conditions (acid and bile concentrations) mimicking the harsh environment of a healthy human gastrointestinal tract (Charteris et al., 1998), safety criteria such as the absence of acquired antibiotic resistance genes, as well as the ability for producing antimicrobial substances (FAO/WHO, 2002; Ogier and Serror, 2008; Rehaiem et al., 2014). Therefore, we investigated the stability of isolated strains for gastric juice and bile salts. Interestingly, 6 strains showed tolerance to both condition indicating their significance to be used as probiotic strains (Table 2). However, probiotic strains are likely to be buffered by food or 
other carrier matrix molecules after consumption and are not likely to be exposed to the extremes of $\mathrm{pH}$ in the stomach (Prasad et al., 1998).

In conclusion, the results obtained in this study showed that six E. faecium strains have great potential to be used as probiotic organisms in human food and/or animal feed. PCR analysis of these strains revealed the genes coding for two enterocins (A and B), whose concomitant production and synergistic activity could be likely more efficient in preventing the growth of undesirable bacteria than a single bacteriocin.

\section{REFERENCES}

ACNFP (1996): Report on Enterococcus faecium Strain K77D. MAFF Advisory Committee on Novel Foods, London.

Aran, H.; Biscola, V.; El-Ghaish, S.; Jaffre, E.; Dousset, X.; Pillot, G.; Haertle, T.; Chobert, J. and Hwanhlem, N. (2015): Bacteriocinproducing Enterococcus faecalis $\mathrm{KT} 2 \mathrm{~W} 2 \mathrm{G}$ isolated from mangrove forests in southern Thailand: Purification, characterization and safety evaluation. Food Control, 54:126-134.

Banwo, K.; Sanni, A. and Tan, H. (2013): Technological properties and probiotic potential of Enterococcus faecium strains isolated from cow milk. J. Appl. Microbiol., 114: 229-241.

Casaus, P.; Nilsen, T.; Cintas, L.M.; Nes, I.F.; Hernández, P.E. and Holo, H. (1997): Enterocin B, a new bacteriocin from Enterococcus faecium T136 which can act synergistically with enterocin A. Microbiology, 143: 2287-2294.

Charteris, W.; Kelly, P.; Morelli, L. and Collins, J. (1998): Development and application of an in vitro methodology to determine the transit tolerance of potentially probiotic Lactobacillus and Bifidobacterium species in the upper human gastrointestinal tract. J. Appl. Microbiol., 84:759-768.

Clinical and Laboratory Standards Institute (2011): Performance standards for antimicrobial susceptibility testing; $21^{\text {st }}$ informational supplement M100-S21. CLSI, Wayne, PA, USA.

Deasy, B.M.; Rea, M.C.; Fitzgerald, G.F.; Cogan, T.M. and Beresford, T.P. (2000): A rapid PCR based method to distinguish between Lactococcus and Enterococcus. Syst. Appl. Microbiol., 23: 510-522.

Dobson, A.; Cotter, P.D.; Ross, R.P. and Hill, C. (2012): Bacteriocin production: a probiotic trait? Appl. Environ. Microbiol.,78: 1-6.

Domig, K.J.; Mayer, H.K. and Kneifel, W. (2003): Methods used for the isolation, enumeration, characterisation and identification of
Enterococcus spp.: 1. Media for isolation and enumeration. Int. J. Food Microbiol., 88: 147164.

Du Toit, M.; Franz, C.; Dicks, L. and Holzapfel, W. (2000): Preliminary characterization of bacteriocins produced by Enterococcus faecium and Enterococcus faecalis isolated from pig faeces. J. Appl. Microbiol., 88: 482494.

Eaton, T.J. and Gasson, M.J. (2001): Molecular Screening of Enterococcus Virulence Determinants and Potential for Genetic Exchange between Food and Medical Isolates. Appl. Environ. Microbiol., 67: 1628-1635.

FAO/WHO. (2002): Guidelines for the evaluation of probiotics in food. Food and Health Agricultural Organisation of the United Nations d World Health Organisation (Working group report).

Fisher, K. and Phillip, P. (2009): The ecology, epidemiology and virulence of Enterococcus. Microbiology, 155: 1749-1757.

Franz, C.M.; Van Belkum, M.J.; Holzapfel, W.H.; Abriouel, H. and Gálvez, A. (2007): Diversity of enterococcal bacteriocins and their grouping in a new classification scheme. FEMS Microbiol. Rev., 31:293-310.

García-Cano, I.; Serrano-Maldonado, C.E.; OlveraGarcía, M.; Delgado-Arciniega, E.; PeñaMontes, C.; Mendoza-Hernández, G. and Quirasco, M. (2014): Antibacterial activity produced by Enterococcus spp. isolated from an artisanal Mexican dairy product, Cotija cheese. LWT-Food Sci. and Tech., 59:26-34.

Giraffa, G. (2003): Functionality of enterococci in dairy products. Int. J. Food Microbiol., 88: 215-222.

Goh, H. and Philip, K. (2015): Isolation and mode of action of bacteriocin BacC1 produced by nonpathogenic Enterococcus faecium C1. J. Dairy Sci. Article in press.

Ishibashi, N.; Himeno, K.; Fujita, K.; Masuda, Y.; Perez, R.H.; Zendo, T.; Wilaipun, P.; Leelawatcharamas, V.; Nakayama, J. and Sonomoto K. (2012): Purification and characterization of multiple bacteriocins and an inducing peptide produced by Enterococcus faecium NKR-5-3 from Thai fermented fish. Biosci. Biotechnol. Biochem., 76: 947-953.

Kariyama, R.; Mitsuhata, R.; Chow, J.W.; Clewell, D.B. and Kumon, H. (2000): Simple and reliable multiplex PCR assay for surveillance isolates of vancomycin-resistant enterococci. J. Clin. Microbiol., 38: 3092-3095.

Lim, S.-M. and Im, D.-S. (2009): Screening and characterization of probiotic lactic acid bacteria isolated from Korean fermented foods. J. Microbiol. Biotechnol., 19: 178-186.

Malek, R.; El-Attar, A.; Mohamed, M.; Anwar, S.; ElSoda, M. and Béal, C. (2012): Technological 
and safety properties display biodiversity among enterococci isolated from two Egyptian cheeses, "Ras" and "Domiati". Int. J. Food Microbiol., 153: 314-322.

Moreno, M.F.; Sarantinopoulos, P.; Tsakalidou, E. and De Vuyst, L. (2006): The role and application of enterococci in food and health. Int. J. Food Microbiol., 106: 1-24.

Ogier, J.-C. and Serror, P. (2008): Safety assessment of dairy microorganisms: the Enterococcus genus. Int. J. Food Microbiol., 126: 291-301.

Prasad, J.; Gill, H.; Smart, J. and Gopal, P.K. (1998): Selection and characterization of Lactobacillus and Bifidobacterium strains for use as probiotics. Int. Dairy J., 8: 993-1002.

Rehaiem, A.; Belgacem, Z.B.; Edalatian, M.R.; Martínez, B.; Rodríguez, A.; Manai, M. and Guerra, N.P. (2014): Assessment of potential probiotic properties and multiple bacteriocin encoding-genes of the technological performing strain Enterococcus faecium MMRA. Food Control, 37: 343-350.

Sánchez, J.; Basanta, A.; Gómez-Sala, B.; Herranz, C.; Cintas, L. and Hernández, P. (2007): Antimicrobial and safety aspects, and biotechnological potential of bacteriocinogenic enterococci isolated from mallard ducks (Anasplatyrhynchos). Int. J. Food Microbiol., 117: 295-305.

Sarantinopoulos, P.; Andrighetto, C.; Georgalaki, M.D.; Rea, M.C.; Lombardi, A.; Cogan, T.M.;
Kalantzopoulos, G. and Tsakalidou, E. (2001): Biochemical properties of enterococci relevant to their technological performance. Int. Dairy J., 11: 621-647.

Tessema, G.T.; Mфretrф, T.; Kohler, A.; Axelsson, L. and Naterstad, K. (2009): Complex phenotypic and genotypic responses of Listeria monocytogenes strains exposed to the class IIabacteriocinsakacin P. Appl. Environ. Microbiol., 75: 6973-6980.

Vandenplas, Y.; Huys, G. and Daube, G. (2015): Probiotics: an update. Jornal de Pediatria (VersãoemPortuguês), 91: 6-21.

Vankerckhoven, V.; Van Autgaerden, T.; Vael, C.; Lammens, C.; Chapelle, S.; Rossi, R.; Jabes, D. and Goossens, H. (2004): Development of a multiplex PCR for the detection of asal, gelE, $c y l A$, esp, and hyl genes in enterococci and survey for virulence determinants among European hospital isolates of Enterococcus faecium. J. Clin. Microbiol., 42: 4473-4479.

Yi, H.; Zhang, L.; Tuo, Y.; Han, X. and Du, M. (2010): A novel method for rapid detection of class IIabacteriocin-producing lactic acid bacteria. Food Control, 21: 426-430.

Zouhir, A.; Hammami, R.; Fliss, I. and Hamida, J.B. (2010): A new structure-based classification of Gram-positive bacteriocins. The Protein J., 29: 432-439.

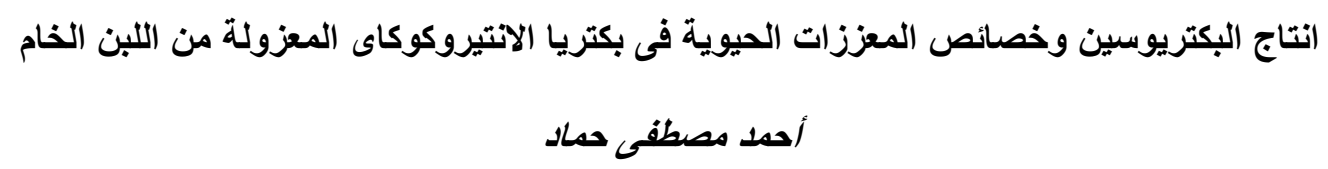

Email: hammad@vet.usc.edu.eg

Assiut University web-site: www.aun.edu.eg

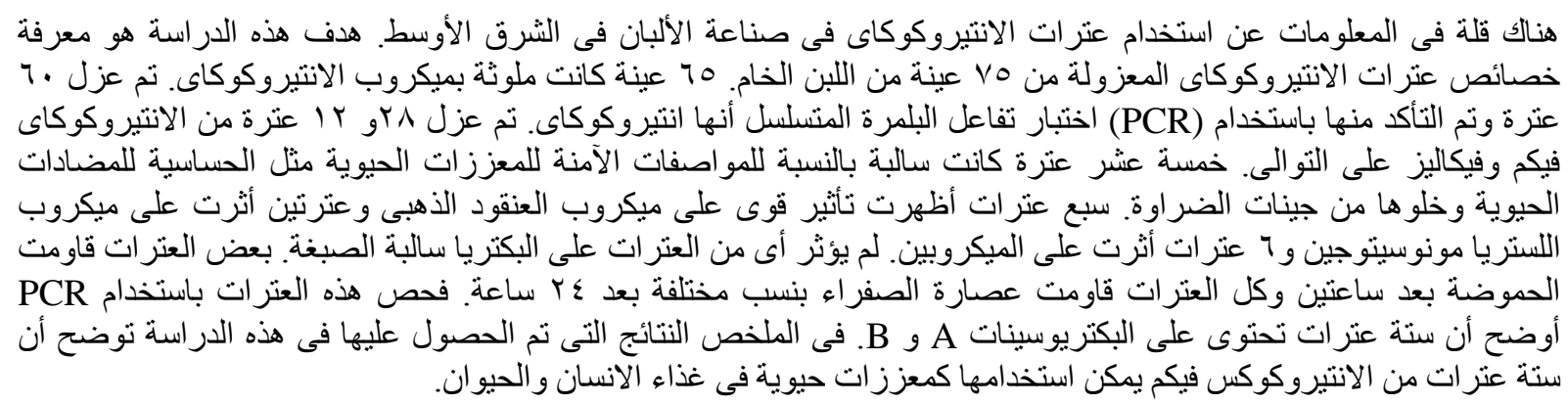

